\title{
Preclinical evaluation of anticataract activity of Mentha spicata leaves on isolated goat lens by an in vitro model
}

\author{
Shreya Mohandas, Saahiba Thaleshwari, Myrene Roselyn Dsouza* (D) \\ Department of Biochemistry, Mount Carmel College Autonomous, Bengaluru - 560052, Karnataka, India.
}

\section{ARTICLE INFO \\ Article history: \\ Received on: December 07, 2020 \\ Accepted on: February 06, 2021 \\ Available online: September 01, 2021}

\section{Key words:}

Antioxidant, antidiabetic, cataract, hyperglycemia, goat lenses, mint

\begin{abstract}
One of the major complications seen in patients with diabetes mellitus is cataract. Many medicinal plants have been used for preventing this major secondary complication. The aim of the current study was to evaluate the anticataract activity of the leaf extract of Mentha spicata extract (ME) on glucose-induced cataractogenesis on isolated goat lens. The freshly isolated goat lenses taken were divided into five experimental groups and incubated for 72 hours: $55 \mathrm{mM}$ glucose alone (Group I), $100 \mu \mathrm{g} / \mathrm{ml} \mathrm{ME}+55 \mathrm{mM}$ glucose (Group II), $300 \mu \mathrm{g} /$ $\mathrm{ml} \mathrm{ME}+55 \mathrm{mM}$ glucose (Group III), $500 \mu \mathrm{g} / \mathrm{ml} \mathrm{ME}+55 \mathrm{mM}$ glucose (Group IV), and $12 \mathrm{ng} / \mathrm{ml}$ Enalapril $+55 \mathrm{mM}$ glucose (Group V), respectively. Various biochemical parameters such as total protein, $\mathrm{H}_{2} \mathrm{O}_{2}$, malondialdehyde (MDA), reduced glutathione, $\mathrm{Cu}^{2+}$-induced lipoprotein dienes, and enzymatic antioxidants like catalase and guaiacol peroxidase were measured in the lens homogenate after incubation. Complete opacity was observed in Group 1 which underwent glucose-induced cataractogenesis correlating with high levels of MDA, reduced amounts of total protein, and enzymatic and non-enzymatic antioxidants compared to Group II. Due to the presence of ME in Group II, pre-oxidative damage to the lenses caused by glucose was prevented. Hence, it was seen that the leaf extract of $M$. spicata prevented glucose-induced oxidative damage in the lenses, which may help in delaying the onset of cataract.
\end{abstract}

\section{INTRODUCTION}

Cataract is defined as the loss of transparency and increased opacity in the crystalline lens of the eye. This may be due to certain abnormalities in lens epithelium, capsular changes, and nuclear changes. There are various causes of cataract such as aging, congenital disorders, and injury to the eye, among which the major one is the secondary complication of diabetes mellitus. Certain inhibitors of $\mathrm{Na}^{+}-\mathrm{K}^{+}$ATPase pumps like Ouabain also function to block the extrusion of sodium ions at the anterior surfaces, leading to the swelling of lens and cataractogenesis. Sugar cataract caused by certain biomolecules, like glucose, xylose, and galactose, is due to its resultant conversion to the respective sugar alcohol by aldose reductase. These, in turn, are impermeable to pass through the lens membrane, leading to accumulation in lens fibers. In these cases, the sugar alcohol thus accumulated leads to an increase in

\footnotetext{
*Corresponding Author

Myrene Roselyn Dsouza, Department of Biochemistry, Mount Carmel

College Autonomous, Bengaluru - 560052, Karnataka, India.

E-mail:myrene83@gmail.com
}

electrolytes which results in the final stages of nuclear opacity [1]. In our body, the glycolytic pathway and pentose shunt helps in the production of glucose, which is later converted to sorbitol by aldose reductase. Sorbitol accumulation causes an imbalance in osmotic homeostasis. Diabetic cataract thereby increases the amount of polyols, leading to the swelling of the epithelial cells, dilution of cellular contents, opaqueness of the cortex, and liquefaction of cortical regions. Increased levels of Nicotinamide Adenine Dinucleotide Hydrogen (NADH) levels seen in diabetic cataract tend to inhibit glycolysis in the cells, limiting the regeneration of Nicotinamide Adenine Dinucleotide $\left(\mathrm{NAD}^{+}\right)$, which further channels glucose conversion into the polyol pathway due to the blockade of the glycolysis pathway, disturbing $\mathrm{NAD}^{+} / \mathrm{NADH}$ ratio in the cells [2].

Various treatments like phacoemulsification, aldose reductase inhibitors, certain antioxidant treatments, and protection against non-enzymatic glycation have been used, but there has been no definite solution for the same $[3,4]$. Certain indigenous plants have also been worked with for the treatment of cataractogenesis. Mentha spicata, having anti-inflammatory, antimicrobial, and anti- 
allergic properties, makes it one of the most used plants for various disorders like respiratory diseases, depression, Alzheimer's, etc. [5]. It also gives protection against atherosclerosis, helps reduce anxiety, and induces antiviral, antiproliferative and neuroprotective properties [6]. These pharmacological aspects have pointed in directions to expand the knowledge of these alkaloids in curing various illnesses. The main objective of the study was to evaluate the hydromethanolic extract of the leaves of $M$. spicata for its in vitro anticataract and antioxidant activities against glucoseinduced cataractogenesis using goat lenses.

\section{METHODOLOGY}

\subsection{Preparation of Plant Extracts}

Fresh leaves of M. spicata were obtained from local markets in Bengaluru, Karnataka, India. To prevent denaturation of the enzymes present in the leaves, they were thoroughly washed and dried at room temperature. Exactly $1 \mathrm{~g}$ of the plant sample was homogenized with $10 \mathrm{ml}$ of ice-cold methanol using a mortar and pestle. The methanol extract was filtered using Whatman's filter paper no. 1 and then centrifuged at $6,000 \mathrm{rpm}$ at $4^{\circ} \mathrm{C}$ for 15 minutes. The supernatant was stored at $4^{\circ} \mathrm{C}$ and used for all assays.

\subsection{Preparation of Lens Culture}

Using goat eye lens, an in vitro analysis of the anticataract activity of $M$. spicata in glucose-induced cataractogenesis was carried out for which the goat's eyeballs were obtained from a slaughterhouse at Shivajinagar, Bengaluru, Karnataka. The lenses were used within 2 hours of killing the animals. The lenses were removed by extra capsular extraction and incubated in artificial aqueous humor (140 mM NaCl, $2 \mathrm{mM} \mathrm{MgCl}, 5 \mathrm{mM} \mathrm{KCl}, 0.5 \mathrm{mM} \mathrm{NaH}\left(\mathrm{PO}_{4}\right)_{2}, 0.5$ $\mathrm{mM} \mathrm{NaHCO}, 0.4 \mathrm{mM} \mathrm{CaCl}_{2}$, and $5.5 \mathrm{mM}$ glucose) at $37^{\circ} \mathrm{C}$ and $\mathrm{pH} 7.8$ for 72 hours. $32 \mathrm{mg} \%$ penicillin and $250 \mathrm{mg} \%$ streptomycin was added to the abovementioned media to avoid any bacterial contamination. $55 \mathrm{mM}$ glucose was used to induce cataract [7].

\subsection{Experimental Design}

Forty-four goat lenses were used in total for the experiment. Five experimental groups were formed as follows:

- Group I: Glucose $55 \mathrm{mM}$ alone (toxic control);

- Group II: Plant sample- - M. spicata $(100 \mu \mathrm{g} / \mathrm{ml})+$ Glucose $55 \mathrm{mM}$;

- Group III: Plant sample-M. spicata $(300 \mu \mathrm{g} / \mathrm{ml})+$ Glucose $55 \mathrm{mM}$;

- Group IV: Plant sample-M. spicata $(500 \mu \mathrm{g} / \mathrm{ml})+$ Glucose $55 \mathrm{mM}$;

- Group V: Standard drug Enalapril (12 ng/ml) + Glucose 55 $\mathrm{mM}$.

\subsection{Photographic Evaluation of Lens Opacity}

The opacity of the lenses was analyzed after 72 hours of incubation by placing the posterior surface of the lenses on a wire mesh. The degree of opacity were graded in the following manner [8]:
- Absence of opacity: 0;

- Slight degree of opacity: +;

- Presence of diffuse opacity: ++;

- Presence of extensive thick opacity: +++ .

\subsection{Preparation of Lens Homogenate}

Each lens was weighed and homogenized using 10 volumes of 0.1 $\mathrm{M}$ potassium phosphate buffer, $\mathrm{pH} 7.0$, in ice-cold condition and centrifuged at $10,000 \mathrm{rpm}$ at $4^{\circ} \mathrm{C}$ for 15 minutes. The supernatant was analyzed for the following biochemical parameters [9].

\subsection{Study of Anticataract Potential}

\subsubsection{Total protein}

Exactly $4.0 \mathrm{ml}$ of alkaline copper reagent was added to $0.02 \mathrm{ml}$ of lens homogenate of plant sample and incubated for 10 minutes at room temperature. $0.4 \mathrm{ml}$ of the Folin-Ciocalteu reagent was added to these test tubes and shaken. Absorbance of the colored samples obtained was taken at $610 \mathrm{~nm}$ using UV-visible spectrophotometer against a suitable blank after 30 minutes of its incubation. The protein content of each was calculated from a standard curve using bovine serum albumin and expressed as $\mathrm{mg} / \mathrm{g}$ lens tissue [10].

\subsubsection{Malondialdehyde (MDA)}

Lipid peroxidation occurring in the lens was analyzed using a modified protocol previously determined by Health and Packer [11]. To $3 \mathrm{ml}$ of extraction buffer $(1.0 \%$ polyvinylpyrolidone, $0.5 \%$ butylated hydroxytoluene, and $0.1 \%$ trichloroacetic acid), $2.0 \mathrm{ml}$ of the lens homogenate was added, mixed and boiled for about 30 minutes, then immediately placed on ice for 5 minutes, followed by centrifugation at $10,000 \mathrm{rpm}$ for 10 minutes at $4^{\circ} \mathrm{C}$. The supernatant obtained was measured at 532 and $600 \mathrm{~nm}$. The difference in the absorbance at 600 and $532 \mathrm{~nm}$ was calculated and deducted from its extinction coefficient of $155 \mathrm{mM}^{-1} \mathrm{~cm}^{-1}$. Values obtained are expressed as MDA g ${ }^{-1}$ lens protein.

\subsubsection{Reduced glutathione (GSH)}

The lens homogenate was prepared with $3 \%$ metaphosphoric acid and centrifuged at $10,000 \mathrm{rpm}$ for 10 minutes at $4^{\circ} \mathrm{C}$. Exactly $0.02 \mathrm{ml}$ of the supernatant with $0.1 \mathrm{M}$ sodium phosphate buffer, $\mathrm{pH} 7.0$, was added to make a total volume of $2.0 \mathrm{ml}$. To this, 0.5 $\mathrm{ml}$ of distilled water and $0.5 \mathrm{ml}$ of Ethylenediamine tetraacetic acid (EDTA) and DTNB solution [6 mM; 5, 5-dithiobis-(-2nitrobenzoic acid) and $2.5 \mathrm{mM}$ EDTA] was added. The tubes were incubated at room temperature for 30 minutes following which the absorbance at $412 \mathrm{~nm}$ was measured. Commercial Reduced glutathione $(\mathrm{GSH})$ was used as standard for establishing the calibration curve [12].

\subsubsection{Hydrogen peroxide}

The lens were homogenized with $0.1 \%$ TCA and centrifuged at $10,000 \mathrm{rpm}$ for 15 minutes at $4^{\circ} \mathrm{C}$. Exactly $0.2 \mathrm{ml}$ of the lens homogenate was added to $1.8 \mathrm{ml}$ of $10 \mathrm{mM}$ sodium phosphate 
buffer, $\mathrm{pH} 7.0$, containing $2.0 \mathrm{ml}$ potassium iodide and incubated at room temperature for 30 minutes. The absorbance at $390 \mathrm{~nm}$ was measured and calculated using a standard curve [13].

\subsubsection{Inhibition of $\mathrm{Cu}^{2+}$-induced lipoprotein diene formation}

The lens homogenate was diluted to $0.67 \%$ in phosphate buffered saline. Copper sulfate was then added to the sample as $\mathrm{CuSO}_{4} \cdot 5 \mathrm{H}_{2} \mathrm{O}$ resulting in the formation of $\mathrm{Cu}^{2+}$ as a result of oxidation. Absorbance at $234 \mathrm{~nm}$ was measured after 120 minutes of incubation at $37^{\circ} \mathrm{C}$ using UV-Vis spectrophotometer. The lipoprotein diene formation was measured to determine the level of tissue protection against any oxidative stress and free radicals [14].

\subsubsection{Statistical analysis}

Statistical analysis was carried out by using one-way analysis of variance, followed by Dunnett's test. Results are expressed as mean \pm Standard Error of Mean (SEM) of four lenses in each group. $p$-values $<0.05$ were considered significant.

\section{RESULTS AND DISCUSSION}

Cataract resulting in opacity of lenses is seen most commonly among the age group 45-50 years due to increase in oxidative stress [15]. In today's practices, replacement and removal of the clouded lenses with intraocular lenses have a higher success rate. Surgical intervention may sometimes result in endophthalmitis or loss of vision [16]. It is therefore imperative to research other areas for reversion of initial stages of cataract, particularly those that have no serious side effects like the use of nutraceuticals or herbal extracts. This paper is an attempt to analyzing the antioxidative and anticataract effect of the methanolic extract of $M$. spicata in glucose-induced goat lenses.

\subsection{Photographic Evaluation of Lens Opacities}

After 72 hours incubation, photographs of normal and experimental lenses were evaluated using a grid mesh. Complete opacity in the lenses belonging to Group I (toxic control) incubated in $55 \mathrm{mM}$ glucose was observed, compared to other lenses (Fig. 1, Table 1). The opacity developed in the lenses with an outward to inward movement toward the end of the 72 hours period. Incubation of the lenses with methanolic extract of mint leaves demonstrated best clarity in Group IV, followed by Group III and II (Table 2 and Fig. 1). The effectiveness of the extract is directly proportional to the clarity of the lenses seen. Lenses incubated in the standard drug 12 ng Enalapril with glucose did not develop any opacity.

\subsection{Effect of M. spicata Extract on Oxidative Stress Markers}

\subsubsection{Malondialdehyde (MDA)}

Oxidative stress acts as one of the biggest causative reasons for cataractogenesis. The activation antioxidant defenses expressed by plant extracts help to delay the onset or prevent cataract. Lipid peroxidation is the process when free radicals take electrons from lipids in cell membranes resulting in loss of membrane fluidity, increase in membrane permeability, and decrease in physiological performance, completely endangering the cell viability. Glucoseinduced cataractogenesis in Group I $(6.04 \pm 0.453514 \mu \mathrm{mol} / \mathrm{g})$ exhibited a remarkable increase in the MDA levels when compared to the lenses which were incubated in the methanolic mint extract $(1.174 \pm 0.007211 \mu \mathrm{mol} / \mathrm{g})$ (Table 2). (a)

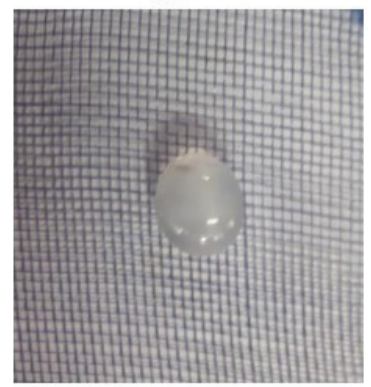

(b)

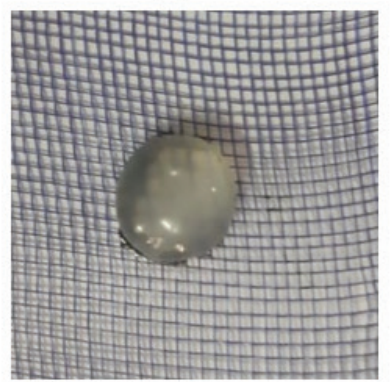

(c)

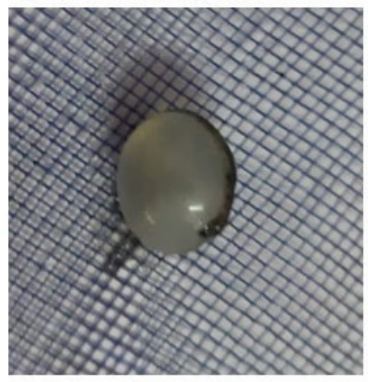

(d)

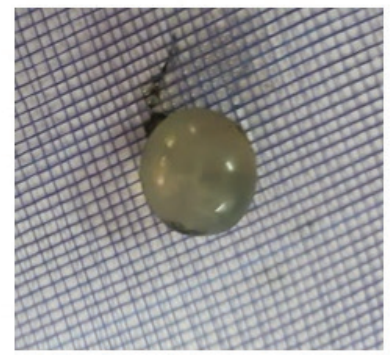

(e)

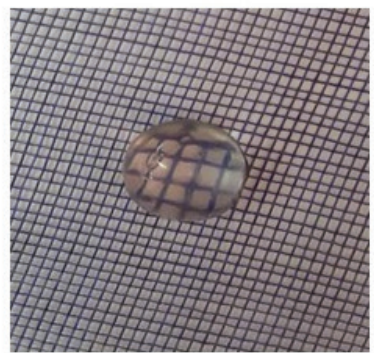

Figure 1. Photographic evaluation of lens opacity after 72-hour incubation with ME. (a) only $55 \mathrm{mM}$ Glucose, (b) $100 \mu \mathrm{g} / \mathrm{ml} \mathrm{ME}+55 \mathrm{mM}$ Glucose, (c) $300 \mu \mathrm{g} / \mathrm{ml} \mathrm{ME}+55 \mathrm{mM}$ Glucose, (d) $500 \mu \mathrm{g} / \mathrm{ml} \mathrm{ME}+55 \mathrm{mM}$ Glucose, and (e) $55 \mathrm{mM}$ Glucose + 12 ng Enalapril. 
Table 1. Effect of methanolic ME. on glucose-induced cataractogenesis.

\begin{tabular}{cllc} 
S. No. & Groups & Treatment & Degree of opacity \\
1 & Group I & $55 \mathrm{mM}$ glucose & +++ \\
2 & Group II & $55 \mathrm{mM}$ glucose $+100 \mu \mathrm{g} / \mathrm{ml} \mathrm{SE}$ & + \\
3 & Group III & $55 \mathrm{mM}$ glucose $+300 \mu \mathrm{g} / \mathrm{ml} \mathrm{SE}$ & ++ \\
4 & Group IV & $55 \mathrm{mM}$ glucose $+500 \mu \mathrm{g} / \mathrm{ml} \mathrm{SE}$ & +++ \\
5 & Group V & $55 \mathrm{mM}$ glucose + Enalpril & 0 \\
\hline
\end{tabular}

The gradation of opacity was graded as follows: $0=$ Absence, $+=$ Slight degree, $++=$ Presence of diffuse opacity, and $+++=$ Presence of extensive thick opacity.

Table 2. Effect of M. spicata on oxidative stress markers using an isolated goat lens model.

\begin{tabular}{lcc}
\multicolumn{1}{c}{ Parameter analyzed } & Control & M. spicata \\
Total protein $(\mu \mathrm{g} / \mathrm{g})$ & $79.4858 \pm 4.072$ & $119.026 \pm 5.137$ \\
$\mathrm{MDA}(\mu \mathrm{mol} / \mathrm{g})$ & $6.04 \pm 0.4535$ & $1.174 \pm 0.0072$ \\
Reduced GSH $(\mu \mathrm{g} / \mathrm{g})$ & $21.04 \pm 2.379$ & $36.45 \pm 0.0975$ \\
Hydrogen peroxide $(\mu \mathrm{mol} / \mathrm{g})$ & $7.41667 \pm 0.79$ & $4.51 \pm 0.09$ \\
Copper-induced lipoprotein diene formation (absorbance) & $1.0086 \pm 0.0005$ & $0.475 \pm 0.030$ \\
\hline
\end{tabular}

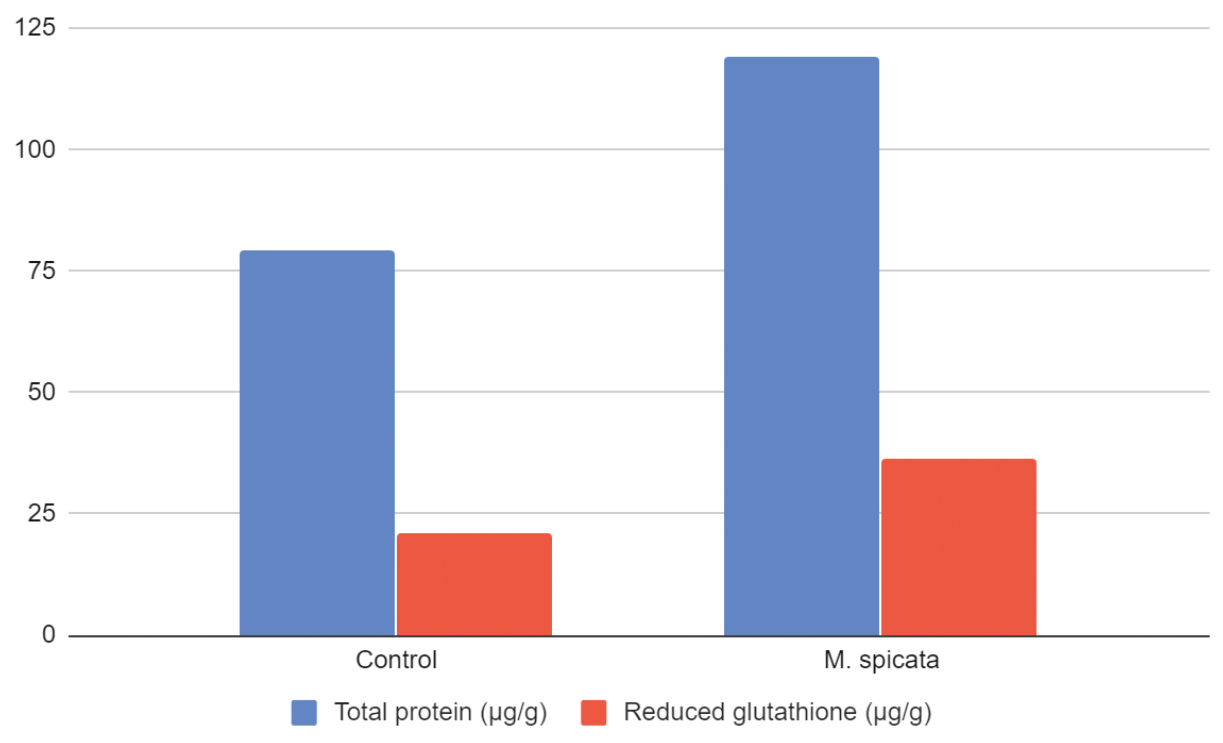

Figure 2. Effects of methanolic extracts of M. spicata on total protein and reduced GSH on isolated goat lens. All values are mean $\pm \mathrm{SD}(n=3)$.

\subsubsection{Reduced GSH}

Antioxidant defenses in plants lead to the reduction in oxidative stress, delaying cataractogenesis. A decrease in levels of GSH is related to cataract formation. In the present investigation, the level of GSH in the lens homogenate of the toxic group was found to be lower $(21.04 \pm 2.37 \mu \mathrm{g} / \mathrm{g})$ in comparison to $100 \mu \mathrm{g} /$ $\mathrm{ml}$ methanolic extract of M. spicata $(36.45 \pm 0.097 \mu \mathrm{g} / \mathrm{g})$ (Fig.2). The reduced form of GSH plays an important role in stabilizing proteins, thus acting as an antioxidant. GSH also helps in protecting and preserving lens clarity. A decrease in GSH leads to an increase in Glutathione disulfide oxidized (GSSG) levels and hence protein crosslinking, decreased solubility, and transparency [17]. Conversion of oxidized GSH (GSSG) to reduced GSH by the enzyme GSH reductase maintains the normal GSH levels in healthy lenses [18]. Reduced GSH levels were found to be restored by MoringaM. oleifera extract, thereby warranting its anticataract potential [19].

\subsubsection{Total soluble lens proteins}

The level of protein was seen to increase in lenses having no cataract development (Table 2). Group I which lacked the sample extract had shown thick opacity. Treatment of lenses with the 


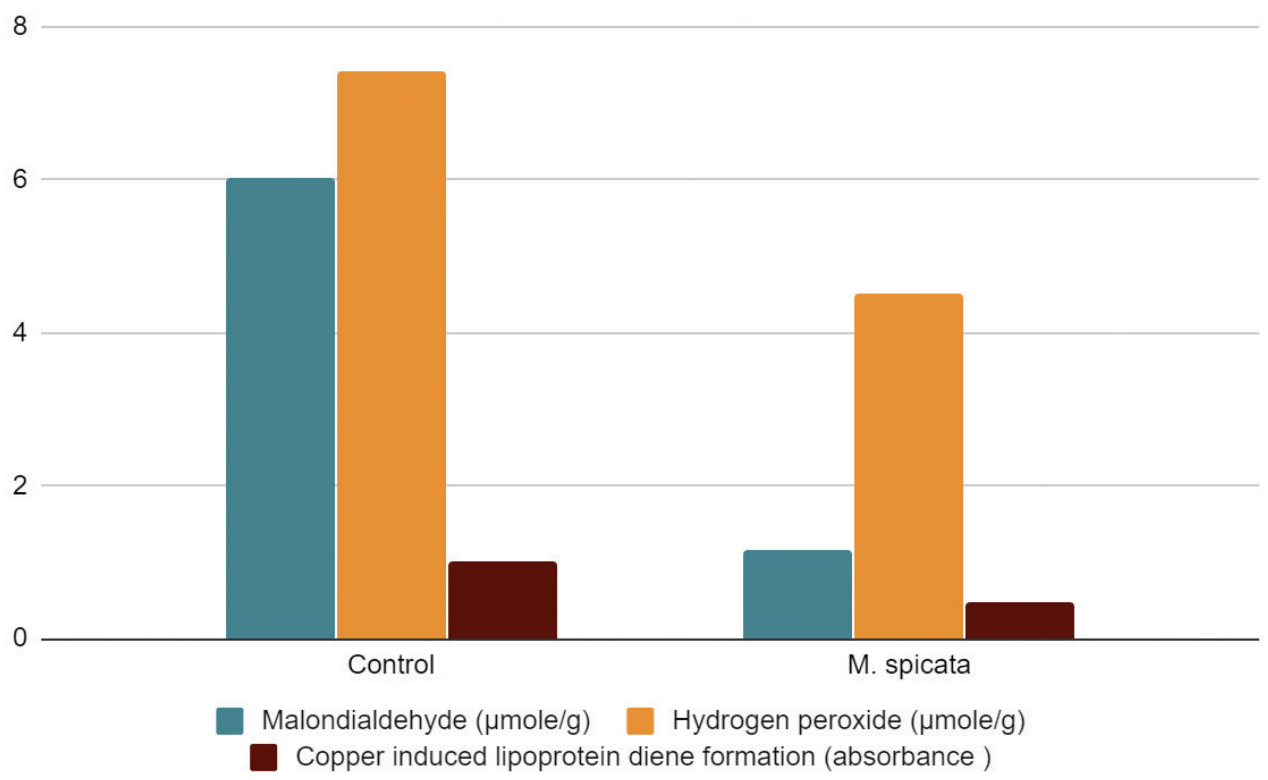

Figure 3. Effects of methanolic extracts of M. spicata on MDA, hydrogen peroxide, and copper-induced lipoprotein diene formation on isolated goat lens. All values are mean $\pm \operatorname{SD}(n=3)$.

extracts has shown a significant increase in the levels of total protein. Total protein levels observed in Group I was found to be $79.4858 \pm 4.072123 \mu \mathrm{g} / \mathrm{g}$, while in Group II of Mentha spicata extract (ME) was $119.026 \pm 5.13761 \mu \mathrm{g} / \mathrm{g}$. Similar results were reported with Spinacia oleracea on glucose-induced cataract lenses [20] and Heliotropium indicum [21].

\subsection{4. $\mathrm{H}_{2} \mathrm{O}_{2}$}

$\mathrm{H}_{2} \mathrm{O}_{2}$ stress has an influence in cataract formation which is justified by the amount of hydrogen peroxide observed in the lenses showing cataract development. High levels of $\mathrm{H}_{2} \mathrm{O}_{2}$ is observed in Group I $(7.41667 \pm 0.79)$ while comparatively low levels of $\mathrm{H}_{2} \mathrm{O}_{2}$ is seen in lenses incubated with ME Group II (4.51 \pm 0.09$)$ along with glucose (Fig. 3). Treatment with other plant extracts have also shown decreased $\mathrm{H}_{2} \mathrm{O}_{2}$ levels in lenses when compared to toxic groups $[18,20]$.

\subsubsection{Copper-induced lipoprotein diene formation}

Copper-induced lipoprotein diene formation is measured by the absorbance at $234 \mathrm{~nm}$. An elevated level in absorbance was noted in Group I (1.0086 \pm 0.0005$)$, while in case of ME an impressive decrease in absorbance $(0.475 \pm 0.030)$ was noted (Fig. 3). The values signify high amounts of diene formation in case of glucose-induced cataractogenesis, which is significantly lowered by the treatment of the plant extract. The lipoprotein diene formation was analyzed by taking absorbance at a time which provides an indication of the protection of ocular tissue against oxidation. A decrease in absorbance at $234 \mathrm{~nm}$ is indicative of the protective action of the extract against oxidative stress. PolyalthiaP. longifolia extracts were shown to provide a protective role by preventing oxidation of lens proteins with researchers claiming that the effect was similar to the standard vitamin E drug [22].

\section{CONCLUSION}

A sedentary lifestyle, population growth, ageing, and increase in obesity are few reasons for the increase in rate of occurrence of diabetes mellitus. An increase in $4.4 \%$ by 2030 is predicted [23]. Diabetes mellitus leads to various secondary complications, the major one being cataract. Certain studies point out the relationship between the loss of lens clarity and hyperglycemia. There is a rapid decline in serum glucose level in patients with hyperglycemic problems which might result in temporary swelling and lens opacification. Numerous advances in cataract surgery have been made to improve the outcome but the same might not be observed for diabetes patients. Side effects like progression of retinopathy, vitreous hemorrhage, iris neovascularization, and decrease or loss of vision have been observed. In vitro analysis of the methanolic extract of M. spicata on the isolated goat lenses, incubated in glucose showed a dose-dependent effect and promising anti-cataract activity against diabetic cataract. Further studies to understand the use of $M$. spicata in the prevention of diabetic cataract needs to be carried out.

\section{ACKNOWLEDGMENTS}

The authors are grateful to Mount Carmel College, Autonomous, Bengaluru, Karnataka, India, for the provision of facilities needed for conducting this project.

\section{AUTHOR CONTRIBUTIONS}

All authors made substantial contributions to conception and design, acquisition of data, or analysis and interpretation of data; took part in drafting the article or revising it critically for important intellectual content; agreed to submit to the current journal; gave final approval of the version to be published; and agree to be accountable for all aspects of the work. All the authors are eligible to be an author as per the international committee of medical journal editors (ICMJE) requirements/guidelines. 


\section{FUNDING}

There is no funding to report.

\section{CONFLICTS OF INTEREST}

The authors report no financial or any other conflicts of interest in this work.

\section{ETHICAL APPROVALS}

Not applicable.

\section{REFERENCES}

1. Kinoshita JH. Mechanisms initiating cataract formation. Proctor Lecture. Invest Ophthalmol 1974;13(10):713-7.

2. Lee AYW, Chung SSM. Contributions of polyol pathway to oxidative stress in diabetic cataract. FASEB J 1999;13:23-30.

3. Pollreisz A, Schmidt-Erfurth U. Diabetic cataract-pathogenesis, epidemiology and treatment. J Ophthalmol 2010;2010:3-4.

4. Kyselova Z, Stefek M, Bauer V. Pharmacological prevention of diabetic cataract. J Diabetes Complications 2004;18:129-40.

5. Sik B, Kapcsándi V, Székelyhidi R, Hanczné EL, Ajtony Z. Recent advances in the analysis of rosmarinic acid from herbs in the Lamiaceae family. Nat Prod Commun 2019; 14(7): 1-10.

6. de Oliveira JR, Camargo SEA, de Oliveira LD. Rosmarinus officinalis L. (rosemary) as therapeutic and prophylactic agent. J Biomed Sci 2019;26(5):14-6.

7. Langade DG, Rao G, Girme RC, Patki PS, Bulakh PM. In vitro prevention by ACE inhibitors of cataract induced by glucose. Ind J Pharmacol 2006;38(2):107-9.

8. Sanderson J, Marcantonio JM, Duncan GA. A human lens model of cortical cataract: $\mathrm{Ca}^{2+}$ induced protein loss, vimentin cleavage and opacification. Invest Ophthalmol Vis Sci 2000;41:2255.

9. Son H, Kim H, Kwon YH. Taurine prevents oxidative damage of high glucose-induced cataractogenesis in isolated rat lenses. J Nutr Sci Vitaminol (Tokyo) 2007;53:324.

10. Lowry OH, Rosebrough NJ, Farr AR, Randoll RJ. Protein measurement with Folin-Phenol reagent. J Biol Chem 1951;193:265-75.

11. Heath RL, Packer L. Photoperoxidation in isolated chlorplasts. Kinetics and stoichiometry of fatty acid peroxidation. Arch Biochem Biophys 1968;125:189-98.

12. Beutler E, Duron O, Kelly BM. Improved method for determination of blood glutathione. J Lab Clin Med 1963;61:882.
13. Velikova V, Yordanov I, Edreva A. Oxidative stress and some antioxidant systems in acid rain treated bean plants: protective role of exogenous polyamines. Plant Sci 2000;151:59-66.

14. Sivashanmugam AT, Chatterjee TK. Anticataractogenesis activity of Polyalthia longifolia leaves extracts against glucose-induced cataractogenesis using goat lenses in vitro. Eur $\mathrm{J}$ Exp Biol 2012;2(1):105-13.

15. Vinson JA. Oxidative stress in cataracts. Pathophysiology 2006;13:151-62.

16. Kessel L, Andresen J, Erngaard D, Flesner P, Tendal B, Hjortdal J. Indication for cataract surgery. Do we have evidence of who wil benefit from surgery? A systematic review and meta-analysis. Acta Ophthalmol 2016;94:10-20.

17. Spector A, and Roy D. Disulphide linked high molecular weight protein associated with human cataract. Proc Natl Acad Sci U S A 1978;75(7): 3244-324-8

18. Dsouza MR. Anticataract activity of galls of Quercus infectoria (Aleppo oak) on glucose-induced cataractogenesis using goat eye lens. Res J Chem Environ 2020;24(11):8-14.

19. Kurmi R, Ganeshpurkar A, Bansal D, Agnihotri A, Dubey N. Ethanol extract of Moringa oliefera prevents in vitro glucose induced cataract on isolated goat eye lens. Indian J Ophthalmol 2014; 62:154-7.

20. Thaleshwari S, Mohandas S, Dsouza MR. Evaluation of anticataractogenic activity of Spinacia oleracea on glucoseinduced cataract in isolated goat lens. Res J Pharm Biol Chem Sci 2020;11(4):45-51.

21. Kyei S, Koffuor GA, Ramkissoon P, Afari C, Asiamah EA. et al. The Cclaim of Aanti-Ccataract Ppotential of Heliotropium indicum: Aa Mmyth or Rreality?. Ophthalmol Ther 2015; 4: 115-128.

22. Sivashanmugam AT, Chatterjee TK. Anticataractogenesis activity of Polyalthia longifolia leaves extracts against glucose-induced cataractogenesis using goat lenses in vitro. European Journal of Experimental Biology 2012; 2 (1):105-1-13.

23. Wild S, Roglic G, Green A, Sicree R, King H. Global prevalence of diabetes: estimates for the year 2000 and projections for 2030 Diabetes Care 2004;27(5):1047-53.

How to cite this article:

Mohandas S, Thaleshwari S, Dsouza MR. Preclinical evaluation of anticataract activity of Mentha spicata leaves on isolated goat lens by an in vitro model. J Appl Biol Biotech 2021; 9(05):39-44. 